\title{
Pyruvate anaplerosis is a mechanism of resistance to pharmacological glutaminase inhibition in triple-receptor negative breast cancer
}

Dean C. Singleton ${ }^{1,2^{*}}$ (D), Anne-Lise Dechaume ${ }^{1}$, Pamela M. Murray ${ }^{1}$, William P. Katt ${ }^{3}$, Bruce C. Baguley ${ }^{1,2}$ and Euphemia Y. Leung ${ }^{1,2^{*}}$

\begin{abstract}
Background: Glutamine serves as an important nutrient with many cancer types displaying glutamine dependence. Following cellular uptake glutamine is converted to glutamate in a reaction catalysed by mitochondrial glutaminase. This glutamate has many uses, including acting as an anaplerotic substrate (via alpha-ketoglutarate) to replenish TCA cycle intermediates. CB-839 is a potent, selective, orally bioavailable inhibitor of glutaminase that has activity in Triple receptor-Negative Breast Cancer (TNBC) cell lines and evidence of efficacy in advanced TNBC patients.

Methods: A panel of eleven breast cancer cell lines was used to investigate the anti-proliferative effects of the glutaminase inhibitors CB-839 and BPTES in different types of culture medium, with or without additional pyruvate supplementation. The abundance of the TCA cycle intermediate fumarate was quantified as a measure if TCA cycle anaplerosis. Pyruvate secretion by TNBC cultures was then assessed with or without AZD3965, a monocarboxylate transporter 1 (MCT1) inhibitor. Finally, two dimensional (2D) monolayer and three dimensional (3D) spheroid assays were used to compare the effect of microenvironmental growth conditions on CB-839 activity.

Results: The anti-proliferative activity of CB-839 in a panel of breast cancer cell lines was similar to published reports, but with a major caveat; growth inhibition by CB-839 was strongly attenuated in culture medium containing pyruvate. This pyruvate-dependent attenuation was also observed with a related glutaminase inhibitor, BPTES. Studies demonstrated that exogenous pyruvate acted as an anaplerotic substrate preventing the decrease of fumarate in CB-839-treated conditions. Furthermore, endogenously produced pyruvate secreted by TNBC cell lines was able to act in a paracrine manner to significantly decrease the sensitivity of recipient cells to glutaminase inhibition. Suppression of pyruvate secretion using the MCT1 inhibitor AZD3965, antagonised this paracrine effect and increased CB-839 activity. Finally, CB-839 activity was significantly compromised in 3D compared with 2D TNBC culture models, suggesting that 3D microenvironmental features impair glutaminase inhibitor responsiveness.

(Continued on next page)
\end{abstract}

\footnotetext{
* Correspondence: d.singleton@auckland.ac.nz; e.leung@auckland.ac.nz

'Auckland Cancer Society Research Centre, School of Medical Sciences,

Faculty of Medical and Health Sciences University of Auckland, Private Bag,

Auckland 92019, New Zealand

Full list of author information is available at the end of the article
}

(c) The Author(s). 2020 Open Access This article is licensed under a Creative Commons Attribution 4.0 International License, which permits use, sharing, adaptation, distribution and reproduction in any medium or format, as long as you give appropriate credit to the original author(s) and the source, provide a link to the Creative Commons licence, and indicate if changes were made. The images or other third party material in this article are included in the article's Creative Commons licence, unless indicated otherwise in a credit line to the material. If material is not included in the article's Creative Commons licence and your intended use is not permitted by statutory regulation or exceeds the permitted use, you will need to obtain permission directly from the copyright holder. To view a copy of this licence, visit http://creativecommons.org/licenses/by/4.0/. The Creative Commons Public Domain Dedication waiver (http://creativecommons.org/publicdomain/zero/1.0/) applies to the data made available in this article, unless otherwise stated in a credit line to the data. 
(Continued from previous page)

Conclusion: This study highlights the potential influence that both circulating and tumour-derived pyruvate can have on glutaminase inhibitor efficacy. Furthermore, it highlights the benefits of 3D spheroid cultures to model the features of the tumour microenvironment and improve the in vitro investigation of cancer metabolism-targeted therapeutics.

Keywords: Glutaminolysis, Glutamine, Pyruvate, Triple-receptor negative breast Cancer, Cancer metabolism, Glutaminase inhibitor

\section{Background}

Cancer cells utilise glutamine to aid in the biosynthetic, bioenergetic and redox needs that are associated with proliferation [1-4]. Many Triple-receptor Negative Breast Cancer (TNBC) cell lines are particularly dependent on glutamine for growth and viability $[5,6]$. These cells acquire glutamine and then convert it to glutamate in a reaction catalysed by mitochondrial glutaminase - predominantly the GAC splice variant encoded by the GLS gene $[5,6]$. The glutamate derived from glutamine has many uses, including glutathione synthesis or further metabolism to $\alpha$-ketoglutarate ( $\alpha \mathrm{KG}$ ) by glutamate dehydrogenase/aminotransferase-catalysed reactions [1, 4]. This $\alpha K G$ contributes to numerous biosynthetic and epigenetic processes or can act as an anaplerotic substrate to replenish tricarboxylic acid (TCA) cycle metabolites that have been exported from the mitochondria for the production of biomass [3]. Once $\alpha K G$ enters the TCA cycle it can support TCA cycle flux either through oxidative decarboxylation or reductive carboxylation [7-11].

This dependence on glutamine anaplerosis renders TNBC cells at increased sensitivity to pharmacological glutaminase inhibition both in vitro and in vivo $[6,12$, 13]. Clinically, glutaminase inhibition is emerging as a promising therapeutic avenue for the management of advanced TNBC. CB-839 (Telaglenastat) is a potent, selective, orally bioavailable first-in-class glutaminase inhibitor that has demonstrated promise in the management of metastatic TNBC in Phase I/II studies $[14,15]$. When combined with paclitaxel, CB-839 was well tolerated with evidence of antitumour activity in heavily pre-treated patients. Yet, although an objective response rate (ORR) of $22 \%$ was observed in the Phase I study (doses $\geq 600 \mathrm{mg}$ BID, $n=27$ ), the outcome of the Phase II study was less encouraging with ORR of $6 \%$ (800 mg BID, $n=16$, “Third Line + " cohort) [14, 15]. A greater mechanistic understanding of the pharmacology of glutaminase inhibition, development of rational drug combinations and the identification and validation of biomarkers may assist in further clinical development of glutaminase inhibitors for TNBC treatment.

While preclinical and clinical studies have confirmed the sensitivity of TNBC to glutaminase inhibition, additional reports in a variety of cancer types have uncovered a set of intrinsic and extrinsic determinants that can impair cellular sensitivity to glutaminase inhibitors. Cells derived from mouse models of non-small cell lung cancer (NSCLC) were highly dependent on glutamine for TCA cycle anaplerosis and proliferation when grown in cell culture but utilised minimal glutamine when grown in vivo, relying instead on glucose metabolism to fuel the TCA cycle [16]. This finding along with results from clinical in vivo and ex vivo isotope tracer studies suggest that the tumour microenvironment has a strong influence on cellular metabolic programmes and the potential to influence the efficacy of metabolismtargeted therapies $[17,18]$.

One possible contributor for the loss of glutamine dependence observed in vivo is the lower cystine concentration in tumours compared with cell culture medium. Growing cells in vitro in physiological concentrations of cystine $(20-50 \mu \mathrm{M})$ suppressed the level of glutamine anaplerosis and subsequently desensitised cells to CB839 [19]. On the contrary, administering cystine to mice increased plasma cystine levels and promoted glutamine anaplerotic flux in subcutaneous tumour xenografts [19]. An additional, intrinsic cellular characteristic is required for this effect; the expression of the glutamate/cystine antiporter $(\mathrm{xCT})$ subunit SLC7A11 promotes this cystine-dependent increase in glutamine utilisation resulting in glutamine dependence [19]. Many oncogenic processes promote the elevated expression of SLC7A11, including KEAP1 mutation and the subsequent NRF2 (NFE2L2)-driven antioxidant response [20].

A number of other metabolites have been identified that can reduce glutamine dependence. For example, increasing the levels of exogenous glutamate can support cell proliferation in times of glutamine deprivation or glutaminase inhibition [20-23]. Likewise, addition of pyruvate or oxaloacetate could prevent apoptosis during acute glutamine deprivation but was unable to support cell proliferation [24]. Addition of extracellular deoxynucleosides was also shown to render TNBC cells resistant to glutamine deprivation [25]. Yet, whether these extrinsic factors contribute to the decrease in glutamine metabolism observed in many tumours compared with in vitro conditions and the potential impact on antitumour activity of glutaminase inhibitors is unknown. 
In this study we investigated a key difference in culture medium composition that can influence the sensitivity of TNBC cell lines to pharmacological glutaminase inhibition. We show that extracellular pyruvate, at physiological concentrations of $20-100 \mu \mathrm{M}$, can significantly impair CB-839 potency in vitro by acting as an anaplerotic substrate. Normal blood pyruvate concentration is reported in the range of $30-150 \mu \mathrm{M}$ [26-28]. Furthermore, we demonstrate that paracrine secretion of de novo produced pyruvate into the extracellular environment can act as a source of pyruvate and this process can be antagonised using a monocarboxylate transporter 1 (MCT1) inhibitor. Our work highlights the potential for both systemic- and paracrine tumour-derived pyruvate to limit the antitumour activity of glutaminase inhibitors and uncovers a possible rational combination that includes addition of MCT1 inhibitor to glutaminase inhibitor therapy.

\section{Methods}

\section{Mammalian cell culture}

Cell lines used in this study were sourced from American Type Culture Collection (Manassas, VA), with the exception of Hs578T (The European Collection of Authenticated Cell Cultures, Salisbury, UK), MDA-MB231-luc-D3H2LN (Caliper Life Sciences, Hopkinton, MA, acquired January 2008) and SUM159PT (Asterand Bioscience, Detroit, MI, acquired January 2010). All cell lines were tested negative for mycoplasma contamination (PlasmoTest ${ }^{\mathrm{Tm}}$ - Mycoplasma Detection kit, InvivoGen, San Diego, CA), but have not been STR authenticated since 2013. Cells were cultured in either RPMI 1640 (11,875,093, ThermoFisher Scientific, Auckland, New Zealand), aMEM (12,000,063, ThermoFisher Scientific) or DMEM $(10,569,010$, ThermoFisher Scientific) supplemented with $5 \% \mathrm{v} / \mathrm{v}$ foetal bovine serum (FBS; Moregate Biotech, Hamilton, New Zealand), as indicated. SUM159PT was routinely cultured in DMEM:F12 (1:1, ThermoFisher Scientific) + 5\% FBS + $1 \mu \mathrm{g} / \mathrm{mL}$ hydrocortisone (Sigma-Aldrich, Auckland, New Zealand) $+5 \mu \mathrm{g} / \mathrm{mL}$ insulin (Sigma-Aldrich).

\section{Chemicals}

CB-839 (S7655, Selleck Chemicals, Houston, TX), Bis-2(5-phenylacetamido-1,3,4-thiadiazol-2-yl) ethyl sulphide (BPTES) (19,284, Cayman Chemical, Ann Arbor, MI) and AZD3965 (S7339, Selleck Chemicals) were dissolved in DMSO to generate $10-25 \mathrm{mM}$ stock solutions, aliquoted and stored at $-20^{\circ} \mathrm{C}$. Sterile $100 \mathrm{mM}$ sodium pyruvate was acquired from ThermoFisher Scientific.

\section{${ }^{3} \mathrm{H}$-thymidine incorporation assay}

Proliferation was measured using a thymidine incorporation assay, as described previously [29]. Briefly, cells were seeded $\left(1-3 \times 10^{3}\right.$ per well) in 96-well plates in the presence of varying concentrations of inhibitor for 3 or 4 days, as indicated. ${ }^{3} \mathrm{H}$-thymidine $(0.04 \mu \mathrm{Ci}$ per well for two dimensional (2D) monolayer culture or $0.08 \mu \mathrm{Ci}$ per well for three dimensional (3D) spheroid culture, see below) was added (6 h for 2D monolayer culture or $16 \mathrm{~h}$ for 3D spheroid culture) prior to harvest, cells were then harvested on glass fiber filters using an automated TomTec harvester. Filters were incubated with Betaplate Scint and thymidine incorporation measured in a Trilux/Betaplate counter. Effects of inhibitors on the incorporation of ${ }^{3} \mathrm{H}$-thymidine into DNA were determined relative to the control (non-drug-treated) samples.

\section{Fumarate assay}

$2.5 \times 10^{5}$ MDA-MB-231 cells were seeded per well of 6 well plates $(140,675$, ThermoFisher Scientific) in $1 \mathrm{~mL}$ of RPMI $1640+5 \%$ FBS. An additional $1 \mathrm{~mL}$ of RPMI $1640+5 \%$ FBS was added containing either CB-839 to a final concentration of $1 \mu \mathrm{M}$ or an equivalent volume of DMSO. $20 \mu \mathrm{L}$ of $100 \mathrm{mM}$ sodium pyruvate (or an equivalent volume of $18.2 \mathrm{M} \Omega \cdot \mathrm{cm}$ at $25^{\circ} \mathrm{C}$ "Milli-Q" water) was added to achieve a final concentration of 1 $\mathrm{mM}$. After $24 \mathrm{~h}$ incubation culture medium was aspirated and cell monolayers were washed twice in cold saline and then lysed on ice using $0.1 \mathrm{~mL}$ of Fumarate Assay Buffer (Fumarate Assay Kit ab102516, Abcam plc). Lysate was transferred into $1.5 \mathrm{~mL}$ microcentrfuge tubes and samples were then centrifuged for $10 \mathrm{~min}$ at $13,000 \times \mathrm{g}$ at $4{ }^{\circ} \mathrm{C}$ to remove debris. The assay was conducted as detailed in the instruction booklet using $50 \mu \mathrm{L}$ of the lysate supernatant. Sample absorbance at $450 \mathrm{~nm}$ was measured in an EnSpire Multimode Plate Reader (PerkinElmer) and fumarate amount (nmol) was interpolated from the standard curve. Lysate protein concentration was then quantified using bicinchoninic acid assay. The amount of fumarate (nmol) was then normalised to either initial number of cells seeded or protein (mg) to account for changes in cell number caused by drug treatment.

\section{Pyruvate assay}

Hs578T $\left(1.5 \times 10^{5}\right)$, MDA-MB-231-luc-D3H2LN $(2.5 \times$ $\left.10^{5}\right)$ or SUM159PT $\left(2.5 \times 10^{5}\right)$ cells were seeded per well of 6-well plates in $1 \mathrm{~mL}$ of RPMI $1640+5 \%$ FBS. An additional $1 \mathrm{~mL}$ of RPMI $1640+5 \%$ FBS was added containing either AZD3965 to a final concentration of $1 \mu \mathrm{M}$ or an equivalent volume of DMSO. After $48 \mathrm{~h}$ incubation, the conditioned culture medium was collected and centrifuged at $800 \times \mathrm{g}$ to pellet floating cells and cell debris. Aliquots of the conditioned culture medium were diluted 1:3 in Pyruvate Assay Buffer (Pyruvate Assay Kit ab65342, Abcam plc) and pyruvate concentrations were quantified according to the instruction booklet. Briefly, 
fluorometric signal at excitation/emission $540 / 590 \mathrm{~nm}$ was measured in an EnSpire Multimode Plate Reader and pyruvate concentration was extrapolated from the standard curve.

\section{Effect of secreted pyruvate on anti-proliferative effect of CB-839}

The conditioned culture medium (or unconditioned RPMI $1640+5 \%$ FBS) described in the pyruvate assay method above was then supplemented with CB-839 to a final concentration of $0.01,0.1,1$ or $10 \mu \mathrm{M}$. MDA-MB231 cells were then grown in this conditioned culture medium and thymidine incorporation was assessed after 3 days growth.

\section{D spheroid cell culture}

On day $0,5 \times 10^{3}$ cells/well were seeded into ultra-low attachment round bottom 96-well plates (7007, Corning, Kennebunk, ME) in ice-cold $50 \mu \mathrm{L}$ RPMI $1640+5 \%$ FBS containing 2.5\% (v/v) Geltrex LDEV-Free Reduced Growth Factor Basement Membrane Matrix (A1413202, ThermoFisher Scientific). The plates were centrifuged at $800 \times \mathrm{g}$ for $10 \mathrm{~min}$ and placed in the cell culture incubator to allow establishment of spheroids. On day 1, $50 \mu \mathrm{L}$ of fresh RPMI $1640+5 \%$ FBS was added to the plates. On day $4,100 \mu \mathrm{L}$ of RPMI $1640+5 \%$ FBS containing CB-839 at $2 \times$ the desired final concentration was added to the spheroid plates. Images of the spheroids were captured using a $10 \times$ objective on a JuLI ${ }^{\text {rm }}$ Stage Real-Time Cell History Recorder (NanoEnTek, Seoul, Korea) on day 4 and day 8 . On day $7{ }^{3} \mathrm{H}$-thymidine was added to the cultures and thymidine incorporation was detected following a $16 \mathrm{~h}$ overnight incubation.

\section{Statistical analysis and graphing}

Statistical analysis and graphing was conducted using Prism (version 8.0.2, GraphPad Software, Inc.). Comparison of two groups was done by unpaired $t$ test. Comparison of three or more groups was done by one-way or two-way analysis of variance (ANOVA) with Dunnett's or Tukey's post hoc test, respectively. Correlation analysis was done using Pearson $r$ correlation coefficient. Values of $P<0.05$ were considered to be statistically significant. All statistical analyses presented represent data from independent studies ( $n \geq 2$, as indicated).

\section{Results}

Breast cancer cell lines display differences in sensitivity to pharmacological glutaminase inhibition depending on culture medium composition

MDA-MB-231 cells grown in $\alpha M E M+5 \%$ FBS (hereafter $\alpha M E M)$ were treated with CB-839 and drug sensitivity was assessed 3 days later by $\mathrm{IC}_{50}$ analysis. The observed $\mathrm{IC}_{50}$ of $3.3 \pm 0.71 \mu \mathrm{M}$ (mean \pm sem, $n=4$ ) was $>100$-fold higher than the reported value of $26 \mathrm{nM}$ [6] (Fig. 1a), albeit using a different endpoint method $\left({ }^{3} \mathrm{H}\right.$ thymidine incorporation versus Promega Cell Titer Glo assay). To understand this discrepancy we treated MDAMB-231 cultures with CB-839 in RPMI $1640+5 \%$ FBS (hereafter RPMI 1640) as used by Gross et al., 2014 and this change in culture medium resulted in an $\mathrm{IC}_{50}$ of $19.3 \pm 9.3 \mathrm{nM}(n=3)$, in strong agreement with the published value (Fig. 1a). MDA-MB-231 cultures were also grown and treated with CB-839 in DMEM + 5\% FBS (hereafter DMEM) and in this case were also relatively insensitive to CB-839 with an $\mathrm{IC}_{50}$ of $5.5 \pm 0.71 \mu \mathrm{M}$ ( $n=$ 2) (Fig. 1a). These findings suggest that the culture medium composition significantly influences the potency of CB-839.

To explore this relationship further, a panel of 10 additional breast cancer cell lines were treated with CB-839 in either RPMI 1640 or aMEM (Fig. 1b). In general, the TNBC cell lines were more sensitive than the receptorpositive cell lines, with the exception of MCF7, in agreement with published reports [6]. CB-839 $\mathrm{IC}_{50}$ values were lower in RPMI 1640 compared with $\alpha$ MEM culture medium in many cell lines tested, with statistically significant effects observed in four cases; BT549, MDAMB-468, Hs578T and SKBR3, and a trend toward an effect in HCC1143 and MCF7. T47D and BT474 displayed no difference in $\mathrm{CB}-839 \mathrm{IC}_{50}$ when cultured in either RPMI 1640 or $\alpha$ MEM.

BPTES, a related allosteric glutaminase inhibitor, was then investigated using the same 11 cell line panel (Fig. 1c). In agreement with the CB-839 observations, BPTES $\mathrm{IC}_{50}$ values were generally lower in RPMI 1640 compared with QMEM culture medium, with statistically significantly lower values observed in BT549, MDA-MB-468 and Hs578T.

\section{Extracellular pyruvate concentrations influence CB-839 potency}

The import and metabolism of extracellular glutamine serves as a key TCA cycle anaplerotic substrate in proliferating cancer cells. Previous reports have highlighted the potential of oxaloacetate, pyruvate, glutamate or cell permeable $\alpha-K G$ (dimethyl $\alpha-K G$ ) to act as alternative anaplerotic substrates that can rescue cell viability during glutamine deprivation and in some cases antagonise the activity of glutaminase inhibitors [25]. We reviewed the composition of the RPMI 1640, $\alpha$ MEM and DMEM formulations used in our studies to identify different components that may be responsible for the difference in sensitivity observed (Supplementary Table S1). Of the numerous different components, one of the key differences noted was sodium pyruvate. While $\alpha M E M$ and DMEM contain $1 \mathrm{mM}$ sodium pyruvate, RPMI 1640 does not contain added pyruvate. We hypothesised that 
A

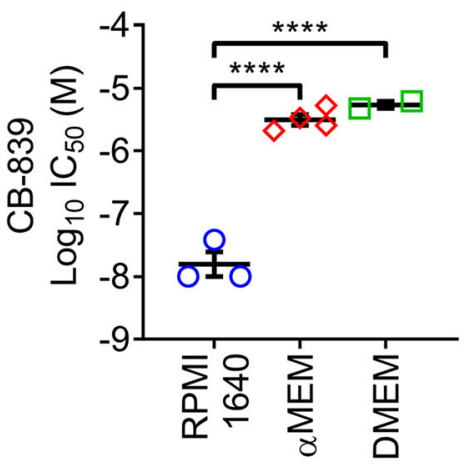

B

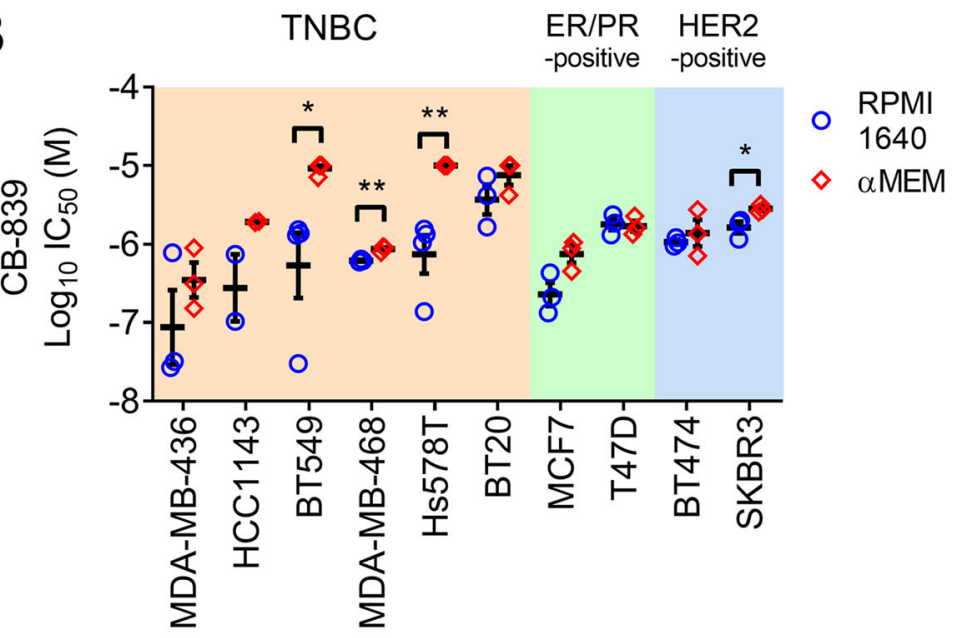

C

TNBC

ER/PR HER2

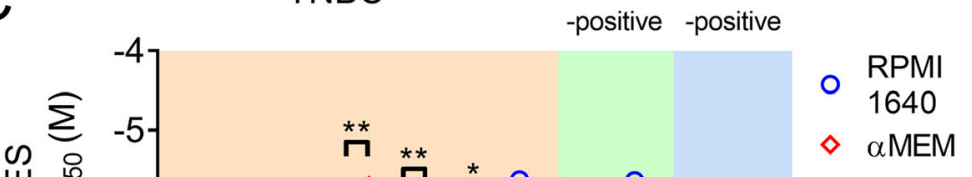

Fig. 1 Breast cancer cell lines display differences in sensitivity to pharmacological glutaminase inhibition depending on culture medium composition. a MDA-MB-231 cells were more sensitive to 3 days CB-839 exposure when assayed in RPMI 1640 + 5\% FBS (RPMI 1640) compared with aMEM + 5\% FBS (aMEM) or DMEM + 5\% FBS (DMEM) (mean \pm SEM, $n=2-4$, one-way ANOVA). CB-839 (b) or BPTES (c) display more potent IC 50 values when assayed in RPMI $1640+5 \%$ FBS compared with aMEM + 5\% FBS in many breast cancer cell lines (mean \pm SEM, $n=2-4$, unpaired t test)

utilisation of extracellular pyruvate by TNBC cells may support mitochondrial anaplerosis, resulting in decreased dependence on glutamine and rendering cells less sensitive to glutaminase inhibition.
To test this hypothesis MDA-MB-231 cultures were treated with CB-839 in RPMI 1640 supplemented with increasing concentrations of sodium pyruvate (Fig. 2a). The introduction of sodium pyruvate resulted in a 


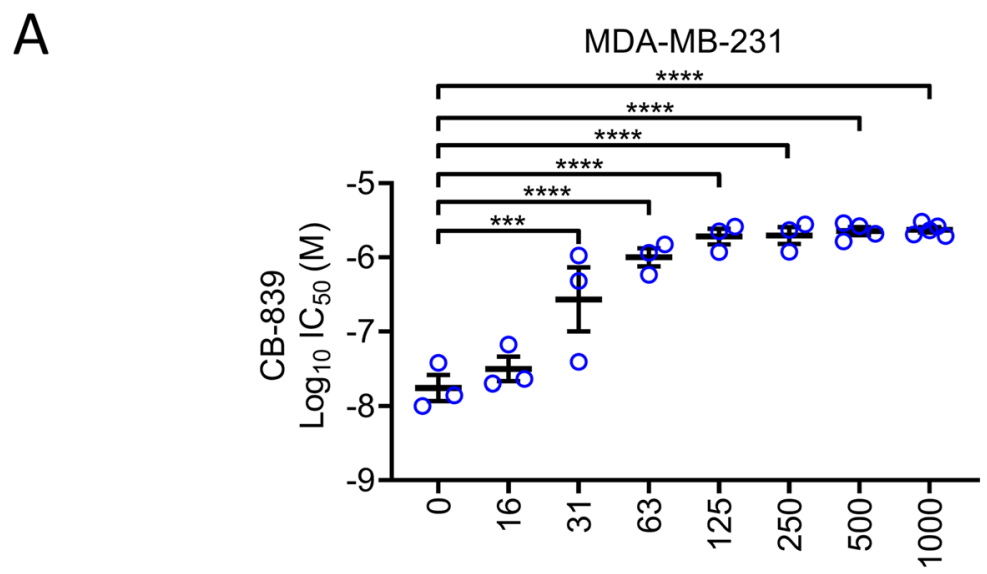

B

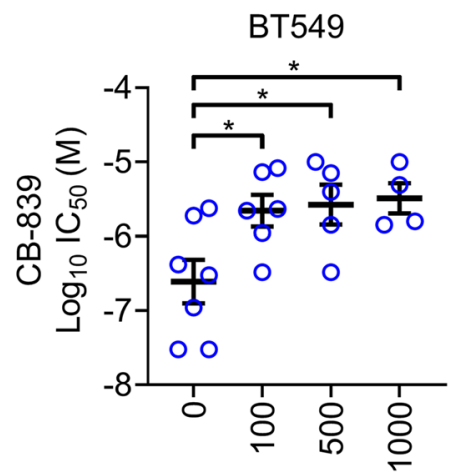

Sodium pyruvate $(\mu \mathrm{M})$

D

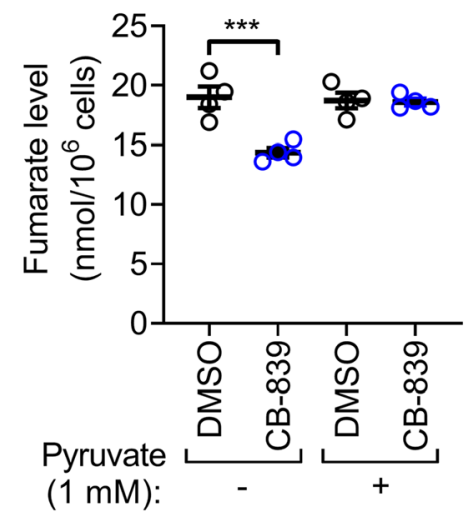

C

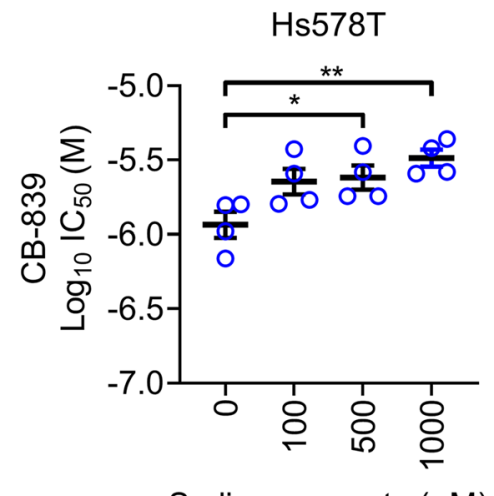

Sodium pyruvate $(\mu \mathrm{M})$

$E$

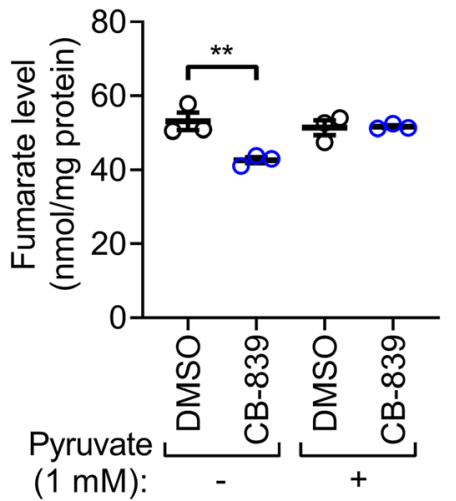

Fig. 2 Pyruvate impairs sensitivity to glutaminase inhibition by increasing TCA cycle anaplerosis. Increasing sodium pyruvate concentration in RPMI $1640+5 \%$ FBS increases CB-839 IC C $_{50}$ (mean \pm SEM, $n=3-7$, one-way ANOVA) in a MDA-MB-231, b BT549 or c Hs578T cells during a 3 day assay. $24 \mathrm{~h}$ treatment with CB-839 decreased fumarate level in MDA-MB-231 cells in RPMI $1640+5 \%$ FBS but not RPMI $1640+5 \%$ FBS supplemented with $1 \mathrm{mM}$ sodium pyruvate. Fumarate level was normalised to either initial cell number seeded (d) or protein amount at endpoint (e) (mean \pm SEM, $n=3-4$, two-way ANOVA)

concentration-dependent increase in the CB-839 $\mathrm{IC}_{50}$ value from $20.7 \pm 8.7 \mathrm{nM}(n=3)$ in the unsupplemented RPMI 1640 to $2.4 \pm 0.2 \mu \mathrm{M} \quad(n=5)$ in the culture medium supplemented with $1 \mathrm{mM}$ sodium pyruvate (mean \pm sem). All pyruvate concentrations above $31 \mu \mathrm{M}$ resulted in statistically significant increases in CB-839 $\mathrm{IC}_{50}$ compared with unsupplemented RPMI 1640.

BT549 and Hs578T also demonstrated pyruvate concentration-dependent changes in glutaminase inhibitor sensitivity (Fig. 2b and c). In BT549 cultures CB-839 
$\mathrm{IC}_{50}$ increased from $0.74 \pm 0.37 \mu \mathrm{M}(n=7)$ in the unsupplemented culture medium to $4.5 \pm 2.0 \mu \mathrm{M}(n=4)$ in the culture medium supplemented with $1 \mathrm{mM}$ sodium pyruvate (mean \pm sem). CB-839 IC $\mathrm{IC}_{50}$ was significantly increased at pyruvate concentrations $\geq 100 \mu \mathrm{M}$. In Hs578T cultures CB-839 $\mathrm{IC}_{50}$ increased from $1.2 \pm 0.2 \mu \mathrm{M}$ in the unsupplemented culture medium to $3.3 \pm 0.4 \mu \mathrm{M}$ in the culture medium supplemented with $1 \mathrm{mM}$ sodium pyruvate $(n=4)$. In this cell line the $\mathrm{CB}-839 \mathrm{IC}_{50}$ was significantly increased at pyruvate concentrations $\geq 500 \mu \mathrm{M}$.

In sensitive cells glutaminase inhibition using CB-839 was reported to decrease the concentration of many TCA cycle intermediates, including malate, citrate and fumarate $[6,23]$. To determine whether exogenous pyruvate can restore TCA cycle intermediates during glutaminase inhibition we assessed steady-state fumarate levels, as a measure of TCA cycle anaplerosis. Cellular fumarate levels were significantly decreased following CB-839 treatment (Fig. 2d and e), in agreement with published findings [6]. Addition of $1 \mathrm{mM}$ sodium pyruvate to RPMI 1640 culture medium prevented this decrease, suggesting that exogenous pyruvate can act as a TCA cycle anaplerotic substrate in TNBC cells when glutamine metabolism is pharmacologically inhibited.

Further studies were conducted to determine whether these effects were dependent to pyruvate carboxylase (PC) activity (Supplementary Figure S1). Treatment with phenylacetic acid (PAA) to inhibit PC was unable to sensitise MDA-MB-231, Hs578T and MCF7 cells to CB-839 in pyruvate-containing culture medium, with a small effect observed in BT549 cells. This finding suggests that in these cell line models replenishment of TCA cycle intermediates by pyruvate during conditions of glutaminase inhibition is largely dependent on the pyruvate dehydrogenase complex and not on PC activity.

The expression of 12 genes involved in pyruvate uptake, mitochondrial transport and metabolism was compared for the 11 breast cancer cell lines using data from the Cancer Cell Line Encyclopedia [30]. The cell lines that did not respond to exogenous pyruvate (T47D and BT474) expressed low levels of MCT genes (Supplementary Table S2). In contrast, the other cell lines that did respond to extracellular pyruvate expressed high levels of either SLC16A1 (MCT1) or SLC16A3 (MCT4). This suggests that MCT expression may be a key determinant that allows extracellular pyruvate to suppress CB-839 response.

\section{Production and paracrine secretion of pyruvate by TNBC cells impairs CB-839 potency}

The pyruvate concentration in RPMI $1640+5 \%$ FBS culture medium was quantified at $2.8 \pm 0.2 \mu \mathrm{M}$ (mean $\pm \mathrm{sem}$, $n=3$, Fig. 3a). As RPMI 1640 does not contain sodium pyruvate the pyruvate detected likely comes from the $5 \%$ $(\mathrm{v} / \mathrm{v})$ serum, in line with an approximate concentration of $50-70 \mu \mathrm{M}$ in the undiluted FBS. We compared pyruvate secretion by three cell lines Hs578T, SUM159PT and a metastatic variant of MDA-MB-231 (MDA-MB-231-lucD3H2LN). After $48 \mathrm{~h}$ culture the resulting pyruvate concentrations in the conditioned culture medium were $58.8 \pm 4.8,61.9 \pm 3.1$ and $83.9 \pm 1.0 \mu \mathrm{M}$ for Hs578T, MDAMB-231-luc-D3H2LN and SUM159PT cells, respectively (Fig. 3a). When treated with the MCT1 inhibitor AZD3965 at $1 \mu \mathrm{M}$ the concentration of pyruvate in the conditioned culture medium was decreased to $28.9 \pm 2.9,56.7 \pm 4.1$ and $62.1 \pm 0.1 \mu \mathrm{M}$ for Hs578T, MDA-MB-231-luc-D3H2LN and SUM159PT cells, respectively (Fig. 3a). Thus, pharmacological MCT1 inhibition can decrease the secretion of pyruvate by TNBC cells into the extracellular environment.

These samples of conditioned (or unconditioned) culture medium were then supplemented with various concentrations of CB-839 and used to culture drug-naïve MDA-MB-231 cells. The conditioned culture medium with the highest concentrations of pyruvate provided resistance to CB-839, in agreement with studies using sodium pyruvate supplementation (Fig. $3 \mathrm{~b}$ and c). Indeed, strong linear correlations were observed between the relative $\%$ of ${ }^{3} \mathrm{H}$-thymidine incorporation and pyruvate concentration in the samples supplemented with CB-839 at all four concentrations, suggesting that higher levels of pyruvate impair CB-839 activity (Fig. 3b). Similarly, when CB-839 $\mathrm{IC}_{50}$ was calculated a strong linear correlation was observed between $\mathrm{CB}-839 \mathrm{IC}_{50}$ and pyruvate concentration, also supporting the hypothesis that higher extracellular levels of pyruvate impair CB-839 activity (Fig. 3c). Notably, the AZD3965-treated samples from all three cell lines (Hs578T, MDA-MB-231-luc-D3H2LN and SUM159PT) provided lower CB-839 $\mathrm{IC}_{50}$ in recipient MDA-MB-231 cells, confirming that MCT1 inhibition can increase CB-839 sensitivity in this in vitro setting.

\section{TNBC cells grown as 3D spheroids display reduced sensitivity to CB-839 compared with 2D cultures}

To investigate the possibility of impaired CB-839 activity due to paracrine environmental effects we used an in vitro 3D spheroid culture model. Following 4 days establishment spheroid cultures were treated with 0.01 , 0.1, 1 or $10 \mu$ M CB-839. MDA-MB-231 and SUM159PT formed regular slow-growing 3D structures (Fig. 4a and b). Hs578T formed regular spherical clusters that displayed minimal increase in size from day 4 to day 8 (Fig. 4c). Microscopic imaging demonstrated minimal effects of CB-839-treatment on spheroid growth/integrity, even after 4 days exposure to $10 \mu \mathrm{M}$ of drug. However, when cell proliferation in these cultures was assessed using ${ }^{3} \mathrm{H}$-thymidine incorporation ( $16 \mathrm{~h}$ overnight incubation from day 7 to day 8), CB-839 caused a clear 


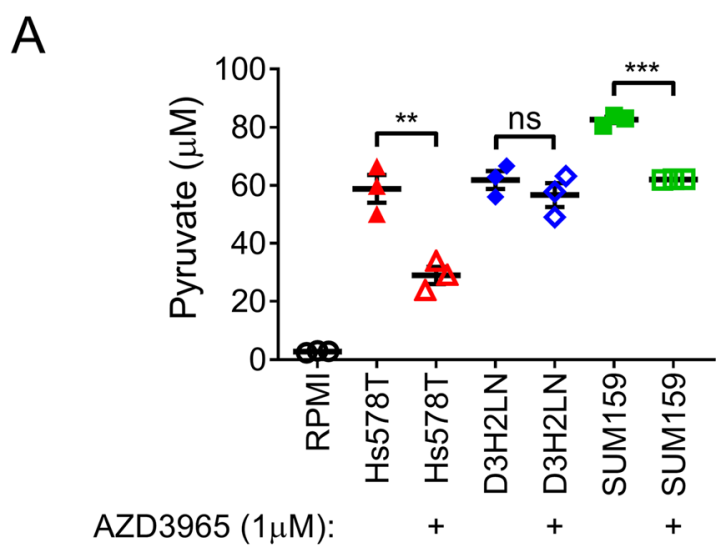

B

$10 \mathrm{nM}$ CB-839 $100 \mathrm{nM}$ CB-839 $1 \mu \mathrm{M}$ CB-839 $10 \mu \mathrm{M}$ CB-839

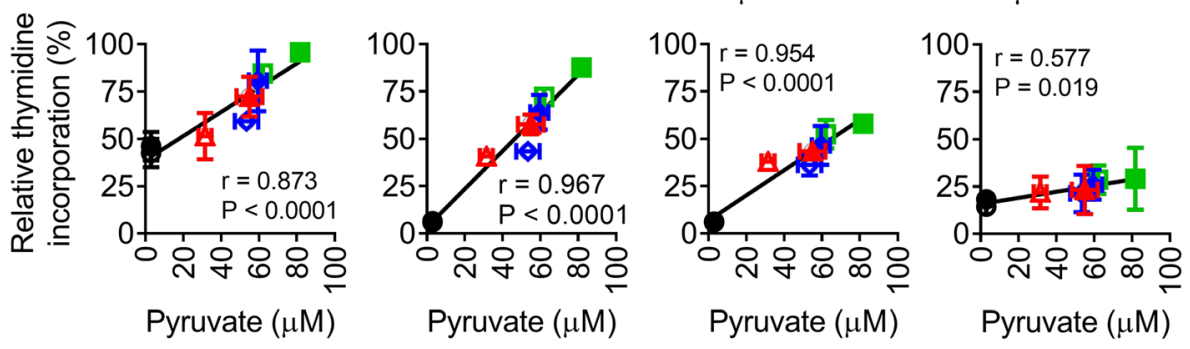

C

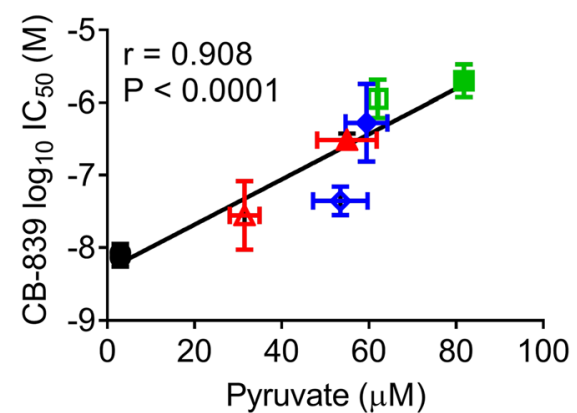

- RPMI

O RPMI + AZD3965

A $\mathrm{Hs} 578 \mathrm{~T}$

$\Delta$ Hs578T + AZD3965

$\rightarrow \mathrm{D} 3 \mathrm{H} 2 \mathrm{LN}$

$\diamond \mathrm{D} 3 \mathrm{H} 2 \mathrm{LN}+\mathrm{AZD} 3965$

SUM159

口 SUM159 + AZD3965

Fig. 3 Pyruvate secreted by TNBC cell lines reduces the potency of CB-839. a Pharmacological MCT1 inhibition using $1 \mu$ M AZD3965 reduced the secretion of pyruvate by Hs578T and SUM159PT (SUM159) but not MDA-MB-231-luc-D3H2LN (D3H2LN) cells. Pyruvate concentration in the conditioned or unconditioned RPMI $1640+5 \%$ FBS (RPMI) culture medium was quantified after $48 \mathrm{~h}$ incubation (mean \pm SEM, $n=3, \mathrm{t}$ test). $\mathbf{b}$ The pyruvate concentration in the conditioned culture medium from a correlates with resistance of recipient MDA-MB-231 cells to CB-839-treatment at $10 \mathrm{nM}, 100 \mathrm{nM}, 1 \mu \mathrm{M}$ or $10 \mu \mathrm{M}$ over 3 days exposure. For each of the TNBC cell lines studied the AZD3965-treated samples of conditioned culture medium demonstrated a decrease in relative thymidine incorporation in recipient MDA-MB-231 cells (mean $\pm S D, n=2$ ). $\mathbf{c} I C_{50}$ analysis also demonstrates a correlation between CB-839 sensitivity and pyruvate concentration in the conditioned culture medium from a (mean \pm SD, $n=2$ ). Correlations were computed by Pearson r correlation coefficient analysis

concentration-dependent decrease in cell proliferation in all three cell lines (Fig. 4d-f). In MDA-MB-231 spheroids the CB-839 concentration needed to halve the relative amount of thymidine incorporation (i.e. $\mathrm{IC}_{50}$ ) was $0.88 \pm$ $0.26 \mu \mathrm{M}$. This change represents a loss in sensitivity of > 100 -fold compared with the $2 \mathrm{D}$ monolayer $\mathrm{IC}_{50}$ of $8.4 \pm$ $0.17 \mathrm{nM}\left(n=4, P=0.015\right.$, $\mathrm{t}$ test). This $2 \mathrm{D} \mathrm{IC}_{50}$ for a 4 day CB-839 exposure was slightly lower than the 19.3 and $20.7 \mathrm{nM} \mathrm{IC} \mathrm{I}_{50}$ values previously observed with 3 day drug exposure (Fig. 1a and 2a).

A 32-fold loss of CB-839 activity was observed in SUM159PT cells when they were grown as 3D spheroids. The $\mathrm{IC}_{50}$ of CB-839 was $5.0 \pm 0.96 \mu \mathrm{M}$ for $3 \mathrm{D}$ cultures compared with $0.15 \pm 0.041 \mu \mathrm{M}$ for $2 \mathrm{D}$ monolayers $(n=4, P=0.003)$. Similarly, a 14 -fold loss of CB-839 activity was observed in $\mathrm{Hs} 578 \mathrm{~T}$ with $3 \mathrm{D} \mathrm{IC}_{50}$ of $6.6 \pm$ 

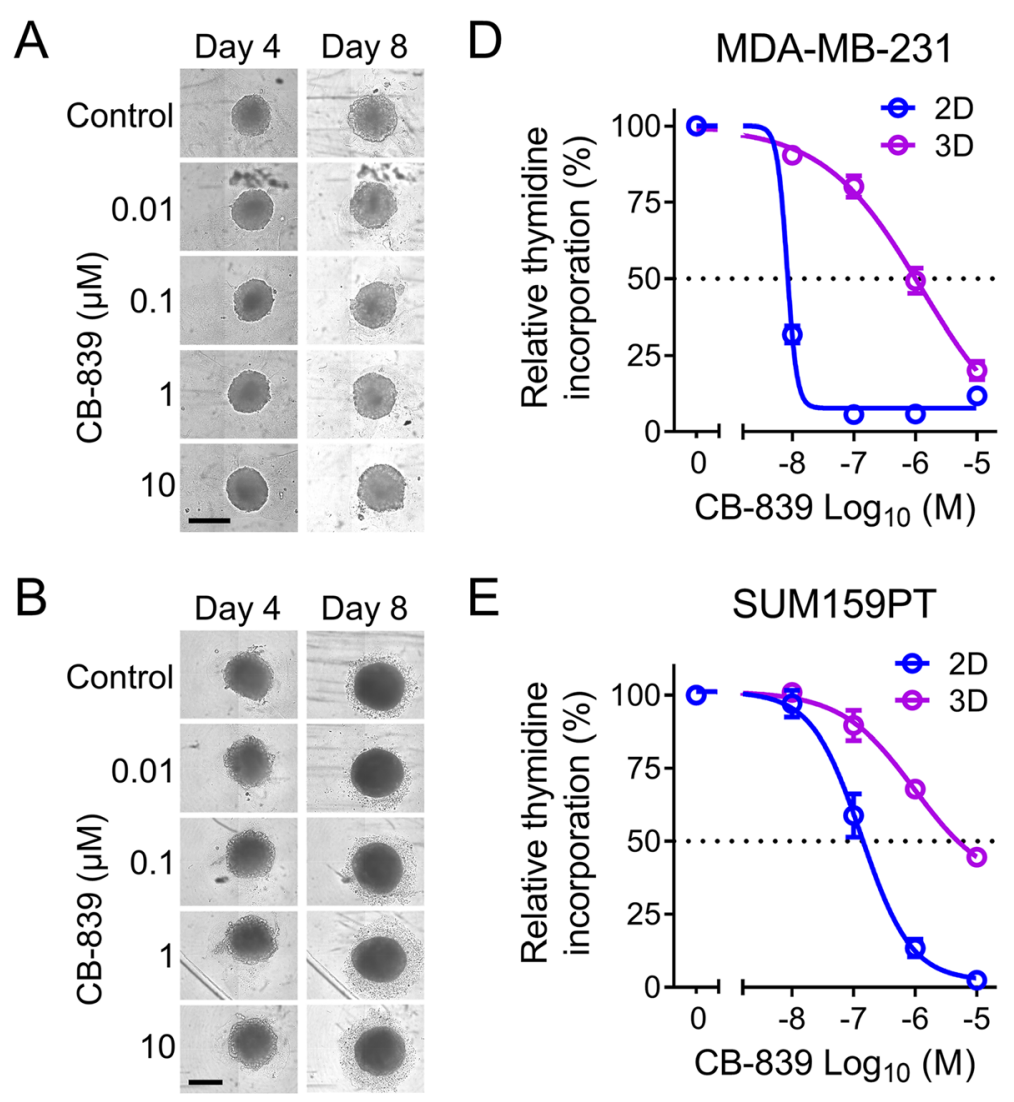

$E$
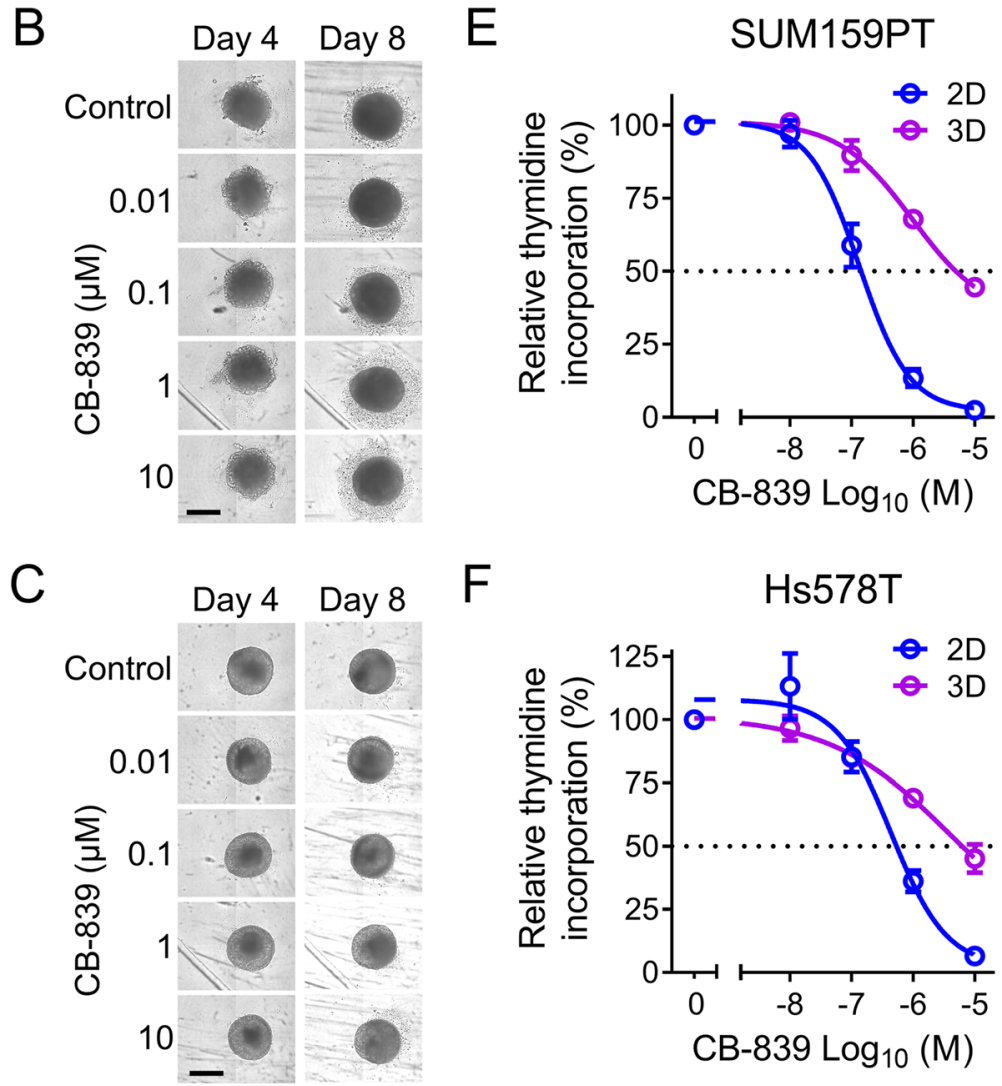

$\mathrm{F}$

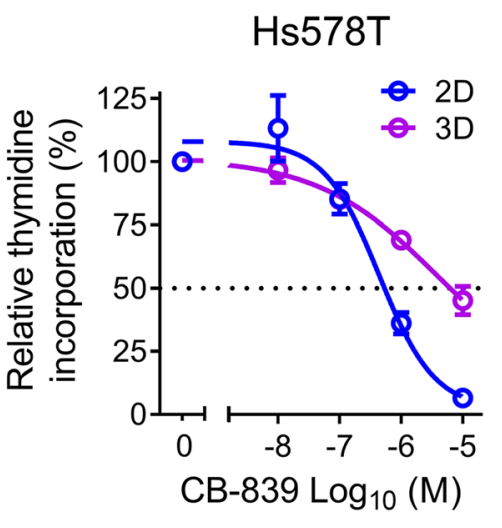

Fig. 4 Activity of CB-839 in 3D spheroid versus 2D monolayer cell cultures. Images of MDA-MB-231 (a), SUM159PT (b) and Hs578T (c) 3D spheroid cell cultures captured on day 4 and 8 (scale bar $=0.5 \mathrm{~mm}$ ). Thymidine incorporation in MDA-MB-231 (d), SUM159PT (e) and Hs578T (f) 3D spheroid cultures and 2D monolayer cultures following 4 days treatment with CB-839 (mean \pm SEM, $n=4-6$ )

$2.0 \mu \mathrm{M}$ compared with $2 \mathrm{D} \mathrm{IC}_{50} 0.45 \pm 0.022 \mu \mathrm{M}(n=4$, $P=0.019$ ). Again, the 4 day drug exposure produced a modestly lower $\mathrm{IC}_{50}$ than the 3 day $\mathrm{IC}_{50}$ of 1.0 and $1.2 \mu \mathrm{M}$ observed previously (Figs. $1 \mathrm{~b}$ and $2 \mathrm{c}$ ). Thus, in the three TNBC cell lines studied CB-839 sensitivity was significantly impaired when cells were grown as 3D spheroids.

The plasma AUC $(0-8 \mathrm{~h})$ in patients treated with CB839 in a $600 \mathrm{mg}$ BID (fed) schedule was approximately $11 \mu \mathrm{M}$ *h with $\mathrm{C}_{\max }$ of $2.3 \mu \mathrm{M}$ and $\mathrm{C}_{\min }$ of $0.65 \mu \mathrm{M}$ [31].
Thus, continuous treatment of the spheroids with CB839 at $1 \mu \mathrm{M}$ represents an approximate exposure which may be achievable in patient tumours. At this concentration there was a substantial decrease in CB-839 sensitivity in all of the spheroid models tested compared with regular 2D cell culture conditions.

\section{Discussion}

Human studies using isotope-labelled glucose or glutamine are providing a clearer understanding of the 
metabolic processes, and heterogeneity therein, that occur in tumours. Whilst lung and brain cancers appear to fuel the TCA cycle via pyruvate dehydrogenase complex-dependent glucose metabolism, the results from studies in clear cell renal cell carcinoma (ccRCC) display supressed glucose oxidation in the TCA cycle, more reflective of the classic "Warburg Effect" observed in most in vitro studies $[17,32]$. In agreement, ${ }^{1-13} \mathrm{C}$-glutamine studies in VHL-deficient ccRCC tumour xenografts confirm that glutamine is a significant anaplerotic nutrient [33]. Other in vitro isotope-labelled tracer findings highlight the requirement for glutamine anaplerosis in conditions of glucose deprivation, a common occurrence in the microenvironment of solid tumours [7]. Notably, isotope-labelled tracer studies have not yet been reported for human TNBC. However, untargeted mass spectrometry-based profiling suggests that glutamine utilisation (glutamate/glutamine ratio) is increased in oestrogen receptor (ER)-negative tumours, at least when compared with ER-positive tumours [15, 34]. Further studies are needed to determine the extent, heterogeneity and products of glutamine metabolism in human TNBC.

The anaplerotic role of glutamine can be bypassed to allow cell survival in glutamine-deprived conditions by utilisation of alternative sources of $\alpha \mathrm{KG}$ to replenish levels of TCA cycle intermediates, for example, exogenously acquired glutamate. This process suggests the potential for a common mechanism of resistance to pharmacological glutaminase inhibition; replenishment of TCA cycle intermediates using alternative anaplerotic substrates. Mechanistically this effect may decrease the bioenergetic stress following glutaminase inhibition and allow more of the decreased available pool of glutamate to be utilised for glutathione biosynthesis (and cystine import) and thus provide greater tolerance to oxidative stress [35].

In preclinical tumour models of pancreatic ductal adenocarcinoma glutaminase inhibition effectively targeted proliferating tumour cells, but was ineffective against the hypoxic subpopulation of cells [22]. The residual tumours following treatment with glutaminase inhibitor displayed metabolic changes including increased glycolysis and glycogenesis, suggestive of adaptive metabolic reprogramming that compromises therapy efficacy. Thus, diverse mechanisms of resistance are emerging as possible means for cancer cells to escape the effects of glutaminase inhibition. Which of these mechanisms occur and are relevant in the response of human tumours to glutaminase inhibition is yet to be definitively established.

Enhanced glutaminolysis is a common feature of many TNBC cell lines that supports cell growth both in vitro and in vivo [36]. Glutamine serves many of the biosynthetic, bioenergetic, epigenetic and redox needs of these cells (Fig. 5a). In this study we demonstrate that the

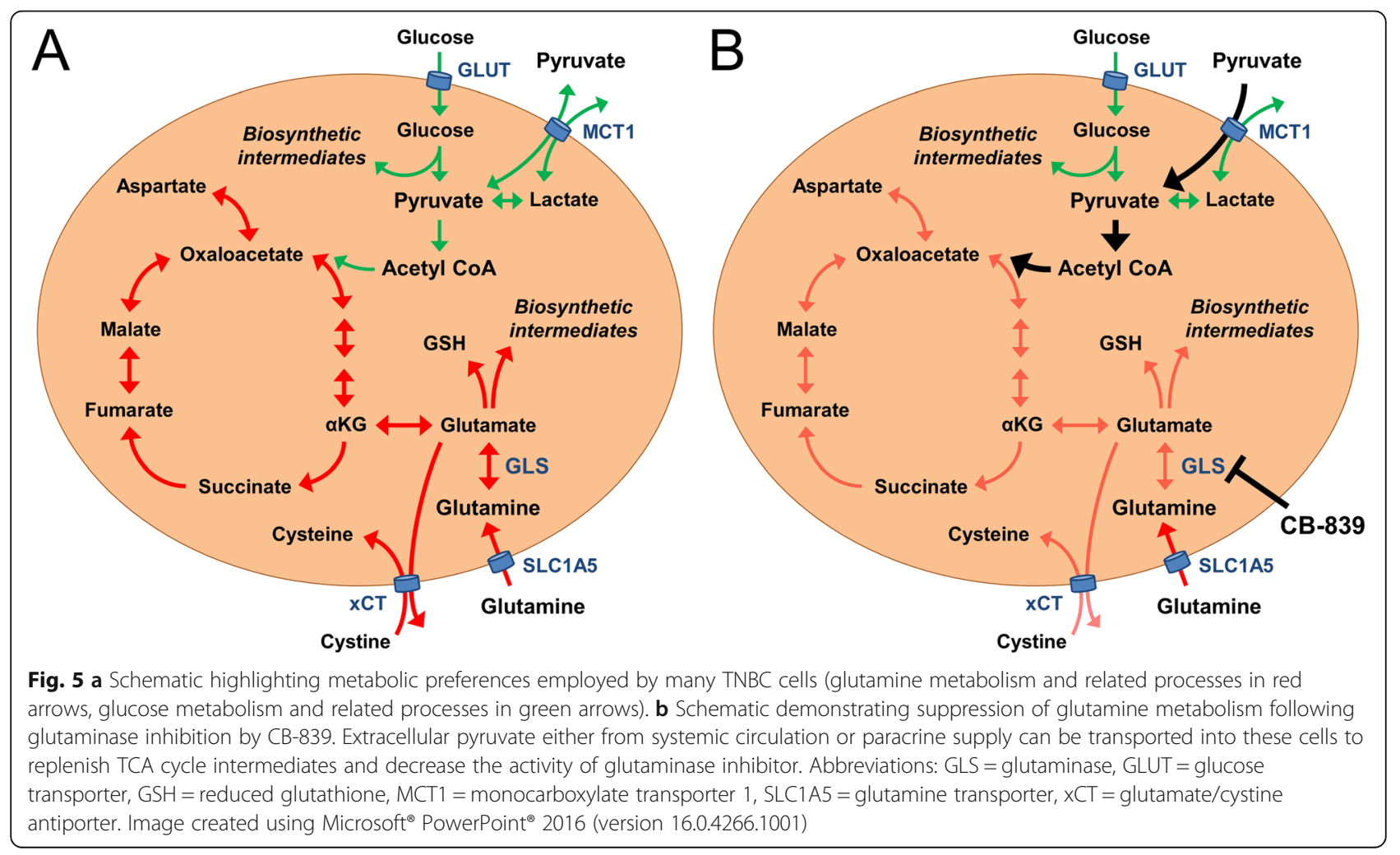


sensitivity of TNBC cell lines to glutaminase inhibition is decreased in culture medium containing pyruvate supplementation. This exogenously added pyruvate was able to rescue levels of the TCA cycle intermediate fumarate in CB-839-treated conditions (Fig. 5b). Furthermore, we examined the levels of endogenously produced pyruvate secreted by TNBC cell lines in culture and show that paracrine supply of pyruvate can significantly reduce the sensitivity of recipient cells to glutaminase inhibition. Of note, our $\mathrm{IC}_{50}$ studies are conducted at low cell density $\left(1-3 \times 10^{3}\right.$ cells/well of a 96 -well plate in $0.12 \mathrm{~mL}$ of culture medium), whereas the pyruvate secretion studies were done at approximately 7.5 -fold higher cell:culture medium ratio $\left(1.5-2.5 \times 10^{5}\right.$ cells/well of a 6 -well plate in $2 \mathrm{~mL}$ of culture medium). Thus, at low cell density/ high culture medium volume there will be minimal opportunity for an autocrine/paracrine effect of pyruvate to impair glutaminase inhibitor activity. This insight highlights the importance of using higher cell density 2D and 3D assays in future studies of metabolism-targeted drugs. More broadly, it also argues for the development and detailed characterisation of new cell culture technologies that closely recapitulate the in vivo tumour microenvironment.

Whist the focus of this study is on pyruvate, it is also possible that lactate might also act in a similar manner. Lactate concentrations are elevated in many cancer types, including breast [37]. Incorporation of ${ }^{13} \mathrm{C}$-lactate into TCA cycle intermediates is extensive, suggesting a major role for lactate as an oxidative fuel [38]. Considering the similarities in pyruvate and lactate transport (by the same MCT transporters) and potential for interconversion catalysed by lactate dehydrogenase (LDH) enzymes, future studies should consider the possible role of lactate in CB-839 responsiveness.

TNBC cells are known to produce and secrete glutamate [39]. This extracellular glutamate (at moderate concentrations) may play an anaplerotic role during conditions of glutamine deprivation. However, glutamate secretion is required for cystine uptake via the $\mathrm{xCT}$ antiporter system and excess accumulation in the extracellular compartment can impair xCT function and limit cystine uptake - a process that is required to support glutaminolysis $[19,39]$. Thus, excessive extracellular glutamate levels may also act in the acquisition of glutamine independence in these models.

To our knowledge this is the first reported usage of 3D spheroid cell culture models as a tool to study the pharmacology of glutaminase inhibitors. Our findings demonstrate that the potency of glutaminase inhibition is impaired in 3D spheroid models compared with the 2D monolayer cultures commonly used for evaluating drug activity. There are a number of potential reasons for this change. The proportion of proliferating cells in
3D models is lower than in 2D cultures resulting in greater cellular heterogeneity within the culture $[40,41]$. The altered nutrient composition, oxygen deprivation and cellular responses including activity of growth signalling cascades and amino acid/hypoxic stress responses may influence glutamine preference. Unequal drug penetration and distribution of CB-839 throughout the spheroid may also impair efficacy compared with $2 \mathrm{D}$ cultures.

Multicellular spheroids represent useful models of many of the microenvironmental characteristics that occur in tumours. Advanced mathematical modelling of these systems can provide key insights into cell proliferation/death, oxygen and nutrient gradients, development of necrosis, and how these compartments interact and change spatially and temporally with spheroid growth and in response to treatment [42]. It has been reported that the anchorage-independent growth conditions of spheroid culture alter glutamine metabolism, favouring reductive carboxylation of glutamine to citrate to support redox homeostasis [43]. Glucose metabolism was also altered in 3D compared with 2D cultures, with lower abundance of glucose-derived citrate suggestive of decreased pyruvate dehydrogenase activity [43]. Whether these effects occur in TNBC spheroid models is yet to be determined.

Another key advantage of 3D spheroids is their relative ease of use. They can be established rapidly (within a few days), grown in 96-well format to enable highthroughput studies, manipulated using conventional multichannel dispensing methods, imaged regularly to monitor growth and treatment effects and can be histologically processed at the study endpoint for more detailed microscopic analysis. Whilst 3D cell culture systems, including cell line-derived spheroids and ex vivo patient-derived organoids, are better models of solid tumour pathophysiology, there is still much work needed to characterise their metabolic alterations (using metabolomic techniques) and define appropriate culture medium compositions to model in vivo conditions. Nonetheless, cell line-derived spheroids, in their current form, represent a useful and cost-effective tool for studying inhibitors of cellular metabolism and testing how they can be combined with other therapies prior to investigations using preclinical tumour models and human subjects.

\section{Conclusion}

Cancer cells grown in vitro display different levels of sensitivity to glutaminase inhibition depending on culture medium composition. A single metabolite, pyruvate, was particularly effective in suppressing the potency of glutaminase inhibitor by contributing to TCA cycle anaplerosis. We build upon this mechanistic observation by 
showing that TNBC cells themselves readily secrete pyruvate into the extracellular environment. This endogenously-derived pyruvate acted in a paracrine manner to decrease the sensitivity of drug-naïve recipient cells to subsequent treatment with CB-839. Blocking this pyruvate secretion, using an MCT1 inhibitor, prevented this process and improved CB-839 activity in the recipient cells. CB-839 potency was also significantly compromised in 3D spheroid compared with $2 \mathrm{D}$ monolayer culture models. These new discoveries highlight the potential influence that circulating and tumourderived pyruvate and other microenvironmental features can have on glutaminase inhibitor efficacy. Future clinical studies to clearly define the metabolomic landscapes of human tumours will help to define which cancer types and tumour features are predictive of response to these agents.

\section{Supplementary information}

Supplementary information accompanies this paper at https://doi.org/10. 1186/s12885-020-06885-3.

Additional file 1: Supplementary Table S1. Comparison of RPMI 1640, aMEM and DMEM culture medium formulation.

Additional file 2: Supplementary Table S2. mRNA expression data (RNAseq; RMA, $\log _{2}$ ) was downloaded from the Cancer Cell Line Encyclopedia for genes involved in pyruvate uptake (SLC16A1, SLC16A7, SLC16A3, SLC16A8, SLC16A4), mitochondrial transport (MPC1, MPC2) and metabolism (PC, PDHA1, DLAT, PDHX, LDHA) for the 11 breast cancer cell lines used in our study. Cell lines that display increased $C B-839 I C_{50}$ in the presence of pyruvate and associated $P$-value are also presented.

Additional file 3: Supplementary Figure S1. Inhibition of Pyruvate Carboxylase using Phenylacetic acid (PAA) does not increase sensitivity to CB-839 in three of four breast cancer cell lines. Cultures were exposed to a titration of CB-839 concentrations in pyruvate-containing aMEM $+5 \%$ FBS with or without $5 \mathrm{mM}$ PAA (Sigma-Aldrich). ${ }^{3} \mathrm{H}$-thymidine incorporation was assayed on day 3 and \% signal plotted relative to CB-839untreated samples. MDA-MB-231 (A), MCF7 (B) and Hs578T (C) did not display any increase in CB-839 sensitivity in the presence of PAA (+PAA). In contrast, BT549 (D) did demonstrate a slight decrease in the CB-839 $I C_{50}$ in the presence of PAA (mean $\pm S D, n=4$, unpaired $t$ test).

\section{Abbreviations}

2D: Two dimensional; 3D: Three dimensional; aKG: a-ketoglutarate; aMEM: Minimum Essential Medium a modification; ANOVA: Analysis of variance; ccRCC: Clear cell renal cell carcinoma; DMEM: Dulbecco's Modified Eagle Medium; DMSO: Dimethyl sulfoxide; ER: Oestrogen receptor; FBS: Foetal bovine serum; GLS: Glutaminase; LDH: Lactate dehydrogenase; MCT: Monocarboxylate transporter; NSCLC: Non-small cell lung cancer; ORR: Objective response rate; PC: Pyruvate carboxylase; RPMI 1640: Roswell Park Memorial Institute 1640 medium; TCA: Tricarboxylic acid; TNBC: Triple receptor-Negative Breast Cancer; xCT: Glutamate/cystine antiporter

\section{Acknowledgments}

The authors thank Dr. Graeme Finlay for helpful discussions.

\section{Authors' contributions}

DCS, WPK, BCB and EYL contributed conception and design of the study; ALD, PMM, DCS and EYL performed, analysed and interpreted the data; DCS wrote the first draft of the manuscript; DCS, WPK and EYL reviewed and revised the manuscript. All authors read and approved the submitted version.

\section{Funding}

The authors would like to acknowledge the support of the New Zealand Breast Cancer Foundation, Breast Cancer Cure and the Heath Research Council of New Zealand [18/750, (DCS)] and the Cancer Society Auckland Northland Senior Fellowship (DCS). DCS and EYL acknowledge support from the New Zealand Breast Cancer Foundation Belinda Scott Science Fellowship. The funders had no role in the study design, data collection, analysis and interpretation, publication decision or writing of the article.

\section{Availability of data and materials}

The datasets during and/or analysed during the current study available from the corresponding author on reasonable request.

Ethics approval and consent to participate

Ethics approval was not required. The cell lines used are all commercially available.

\section{Consent for publication}

Not applicable.

\section{Competing interests}

The authors declare that the research was conducted in the absence of any commercial or financial relationships that could be construed as a potential conflict of interest.

\section{Author details}

${ }^{1}$ Auckland Cancer Society Research Centre, School of Medical Sciences, Faculty of Medical and Health Sciences University of Auckland, Private Bag, Auckland 92019, New Zealand. ${ }^{2}$ Maurice Wilkins Centre for Molecular Biodiscovery, University of Auckland, Symonds Street, Auckland 1010, New Zealand. ${ }^{3}$ Department of Molecular Medicine, Cornell University, Ithaca, New York 14853, USA.

Received: 13 February 2020 Accepted: 21 April 2020

Published online: 25 May 2020

\section{References}

1. Altman BJ, Stine ZE, Dang CV. From Krebs to clinic: glutamine metabolism to cancer therapy. Nat Rev Cancer. 2016;16(10):619-34.

2. Pavlova NN, Thompson CB. The emerging hallmarks of Cancer metabolism. Cell Metab. 2016:23(1):27-47.

3. Zhang J, Pavlova NN, Thompson CB. Cancer cell metabolism: the essential role of the nonessential amino acid, glutamine. EMBO J. 2017; 36(10):1302-15.

4. Still ER, Yuneva MO. Hopefully devoted to Q: targeting glutamine addiction in cancer. Br J Cancer. 2017:116(11):1375-81.

5. Timmerman LA, Holton T, Yuneva M, Louie RJ, Padro M, Daemen A, Hu M, Chan DA. Ethier SP, van 't veer $\amalg$ et al: glutamine sensitivity analysis identifies the $\mathrm{xCT}$ antiporter as a common triple-negative breast tumor therapeutic target. Cancer Cell. 2013;24(4):450-65.

6. Gross MI, Demo SD, Dennison JB, Chen L, Chernov-Rogan T, Goyal B, Janes $J R$, Laidig GJ, Lewis ER, Li J, et al. Antitumor activity of the glutaminase inhibitor CB-839 in triple-negative breast cancer. Mol Cancer Ther. 2014; 13(4):890-901

7. Le A, Lane AN, Hamaker M, Bose S, Gouw A, Barbi J, Tsukamoto T, Rojas CJ, Slusher BS, Zhang $\mathrm{H}$, et al. Glucose-independent glutamine metabolism via TCA cycling for proliferation and survival in B cells. Cell Metab. 2012;15(1): $110-21$

8. Sun RC, Denko NC. Hypoxic regulation of glutamine metabolism through HIF1 and SIAH2 supports lipid synthesis that is necessary for tumor growth. Cell Metab. 2014;19(2):285-92.

9. Mullen AR, Wheaton WW, Jin ES, Chen PH, Sullivan LB, Cheng T, Yang Y, Linehan WM, Chandel NS, DeBerardinis RJ. Reductive carboxylation supports growth in tumour cells with defective mitochondria. Nature. 2011;481(7381): 385-8.

10. Metallo CM, Gameiro PA, Bell EL, Mattaini KR, Yang J, Hiller K, Jewell CM, Johnson ZR, Irvine DJ, Guarente L, et al. Reductive glutamine metabolism by IDH1 mediates lipogenesis under hypoxia. Nature. 2011;481(7381):380-4

11. Wise DR, Ward PS, Shay JE, Cross JR, Gruber JJ, Sachdeva UM, Platt JM, DeMatteo RG, Simon MC, Thompson CB. Hypoxia promotes isocitrate dehydrogenase-dependent carboxylation of alpha-ketoglutarate to citrate to 
support cell growth and viability. Proc Natl Acad Sci U S A. 2011;108(49): 19611-6.

12. Huang Q, Stalnecker C, Zhang C, McDermott LA, lyer P, O'Neill J, Reimer S, Cerione RA, Katt WP. Characterization of the interactions of potent allosteric inhibitors with glutaminase C, a key enzyme in cancer cell glutamine metabolism. J Biol Chem. 2018;293(10):3535-45.

13. McDermott LA, lyer $P$, Vernetti L, Rimer S, Sun J, Boby M, Yang T, Fioravanti $M, O$ Neill J, Wang $L$, et al. Design and evaluation of novel glutaminase inhibitors. Bioorg Med Chem. 2016;24(8):1819-39.

14. Vidal G, Kalinsky K, Stringer-Reasor E, Lynce F, Cole J, Valdes-Albini F, Soliman H, Nikolinakos P, Silber A, DeMichele A et al: Abstract P6-20-07: Efficacy and safety of CB-839, a small molecule inhibitor of glutaminase, in combination with paclitaxel in patients with advanced triple negative breast cancer (TNBC): Initial findings from a multicenter, open-label phase 2 study. 2019, 79(4 Supplement):P6-20-07.

15. Kalinsky K, Harding J, DeMichele A, Infante J, Gogineni K, Owonikoko T, Isakoff S, Iliopoulos O, Patel M, Munster P et al: Abstract PD3-13: Phase 1 study of CB-839, a first-in-class oral inhibitor of glutaminase, in combination with paclitaxel in patients with advanced triple negative breast cancer. 2018, 78(4 Supplement):PD3-13-PD13-13.

16. Davidson SM, Papagiannakopoulos T, Olenchock BA, Heyman JE, Keibler MA, Luengo A, Bauer MR, Jha AK, O'Brien JP, Pierce KA, et al. Environment impacts the metabolic dependencies of Ras-driven non-small cell lung Cancer. Cell Metab. 2016;23(3):517-28.

17. Hensley CT, Faubert B, Yuan Q, Lev-Cohain N, Jin E, Kim J, Jiang L, Ko B, Skelton R, Loudat $L$, et al. Metabolic heterogeneity in human lung tumors. Cell. 2016;164(4):681-94.

18. Sellers K, Fox MP, Bousamra M 2nd, Slone SP, Higashi RM, Miller DM, Wang Y, Yan J, Yuneva MO, Deshpande R, et al. Pyruvate carboxylase is critical for non-small-cell lung cancer proliferation. J Clin Invest. 2015;125(2):687-98.

19. Muir A, Danai LV, Gui DY, Waingarten CY, Lewis CA, Vander Heiden MG. Environmental cystine drives glutamine anaplerosis and sensitizes cancer cells to glutaminase inhibition. eLife. 2017;6:e27713. Published 2017 Aug 15. https://doi.org/10.7554/eLife.27713.

20. Sayin VI, LeBoeuf SE, Singh SX, Davidson SM, Biancur D, Guzelhan BS, Alvarez SW, Wu WL, Karakousi TR, Zavitsanou AM, et al. Activation of the NRF2 antioxidant program generates an imbalance in central carbon metabolism in cancer. eLife. 2017;6:e28083. Published 2017 Oct 2. https:// doi.org/10.7554/eLife.28083.

21. Son J, Lyssiotis CA, Ying $H$, Wang $X$, Hua S, Ligorio M, Perera RM, Ferrone CR, Mullarky E, Shyh-Chang N, et al. Glutamine supports pancreatic cancer growth through a KRAS-regulated metabolic pathway. Nature. 2013; 496(7443):101-5.

22. Elgogary A, Xu Q, Poore B, Alt J, Zimmermann SC, Zhao L, Fu J, Chen B, Xia S, Liu Y, et al. Combination therapy with BPTES nanoparticles and metformin targets the metabolic heterogeneity of pancreatic cancer. Proc Natl Acad Sci U S A. 2016;113(36):E5328-36.

23. Biancur DE, Paulo JA, Malachowska B, Quiles Del Rey M, Sousa CM, Wang X, Sohn ASW, Chu GC, Gygi SP, Harper JW, et al. Compensatory metabolic networks in pancreatic cancers upon perturbation of glutamine metabolism. Nat Commun. 2017:8:15965.

24. Yuneva M, Zamboni N, Oefner P, Sachidanandam R, Lazebnik Y. Deficiency in glutamine but not glucose induces MYC-dependent apoptosis in human cells. J Cell Biol. 2007;178(1):93-105.

25. Patel D, Menon D, Bernfeld E, Mroz V, Kalan S, Loayza D, Foster DA. Aspartate rescues S-phase arrest caused by suppression of glutamine utilization in KRas-driven Cancer cells. J Biol Chem. 2016;291(17):9322-9.

26. Olek RA, Kujach S, Wnuk D, Laskowski R. Single sodium pyruvate ingestion modifies blood acid-base status and post-exercise lactate concentration in humans. Nutrients. 2014;6(5):1981-92.

27. Landon J, Fawcett JK, Wynn V. Blood pyruvate concentration measured by a specific method in control subjects. J Clin Pathol. 1962;15:579-84.

28. Daly ME, Vale C, Walker M, Littlefield A, Alberti KG, Mathers JC. Acute effects on insulin sensitivity and diurnal metabolic profiles of a high-sucrose compared with a high-starch diet. Am J Clin Nutr. 1998;67(6):1186-96.

29. Leung EY, Kim JE, Askarian-Amiri M, Rewcastle GW, Finlay GJ, Baguley BC. Relationships between signaling pathway usage and sensitivity to a pathway inhibitor: examination of trametinib responses in cultured breast cancer lines. PLoS One. 2014;9(8):e105792.

30. Barretina J, Caponigro G, Stransky N, Venkatesan K, Margolin AA, Kim S, Wilson CJ, Lehar J, Kryukov GV, Sonkin D, et al. The Cancer cell line encyclopedia enables predictive modelling of anticancer drug sensitivity. Nature. 2012:483(7391):603-7.

31. Harding JJ, Telli ML, Munster PN, Le MH, Molineaux C, Bennett MK, Mittra E, Burris HA, Clark AS, Dunphy M et al: Safety and tolerability of increasing doses of CB-839, a first-in-class, orally administered small molecule inhibitor of glutaminase, in solid tumors. 2015, 33(15_suppl):2512.

32. Courtney KD, Bezwada D, Mashimo T, Pichumani K, Vemireddy V, Funk AM, Wimberly J, McNeil SS, Kapur P, Lotan Y, et al. Isotope tracing of human clear cell renal cell carcinomas demonstrates suppressed glucose oxidation in vivo. Cell Metab. 2018;28(5):793-800 e792.

33. Gameiro PA, Yang J, Metelo AM, Perez-Carro R, Baker R, Wang Z, Arreola A, Rathmell WK, Olumi A, Lopez-Larrubia P, et al. In vivo HIF-mediated reductive carboxylation is regulated by citrate levels and sensitizes VHLdeficient cells to glutamine deprivation. Cell Metab. 2013;17(3):372-85.

34. Terunuma A, Putluri N, Mishra P, Mathe EA, Dorsey TH, Yi M, Wallace TA, Issaq HJ, Zhou M, Killian JK, et al. MYC-driven accumulation of 2hydroxyglutarate is associated with breast cancer prognosis. J Clin Invest. 2014;124(1):398-412.

35. Daemen A, Liu B, Song K, Kwong M, Gao M, Hong R, Nannini M, Peterson D, Liederer BM, de la Cruz C, et al. Pan-Cancer metabolic signature predicts codependency on Glutaminase and De novo glutathione synthesis linked to a high-Mesenchymal cell state. Cell Metab. 2018;28(3):383-99 e389.

36. Lampa M, Arlt H, He T, Ospina B, Reeves J, Zhang B, Murtie J, Deng G, Barberis C, Hoffmann D, et al. Glutaminase is essential for the growth of triple-negative breast cancer cells with a deregulated glutamine metabolism pathway and its suppression synergizes with MTOR inhibition. PLoS One. 2017;12(9):e0185092.

37. de la Cruz-Lopez KG, Castro-Munoz LJ, Reyes-Hernandez DO, GarciaCarranca A, Manzo-Merino J. Lactate in the regulation of tumor microenvironment and therapeutic approaches. Front Oncol. 2019;9:1143.

38. Hui S, Ghergurovich JM, Morscher RJ, Jang C, Teng X, Lu W, Esparza LA, Reya T, Le Z, Yanxiang Guo J, et al. Glucose feeds the TCA cycle via circulating lactate. Nature. 2017;551(7678):115-8.

39. Briggs KJ, Koivunen P, Cao S, Backus KM, Olenchock BA, Patel H, Zhang Q, Signoretti S, Gerfen GJ, Richardson AL, et al. Paracrine induction of HIF by glutamate in breast Cancer: EgIN1 senses cysteine. Cell. 2016;166(1):126-39.

40. Melissaridou S, Wiechec E, Magan M, Jain MV, Chung MK, Farnebo L, Roberg $K$. The effect of 2D and 3D cell cultures on treatment response, EMT profile and stem cell features in head and neck cancer. Cancer Cell Int. 2019;19:16.

41. Riedl A, Schlederer M, Pudelko K, Stadler M, Walter S, Unterleuthner D, Unger C, Kramer N, Hengstschlager M, Kenner L, et al. Comparison of cancer cells in 2D vs 3D culture reveals differences in AKT-mTOR-S6K signaling and drug responses. J Cell Sci. 2017;130(1):203-18.

42. Mao X, McManaway S, Jaiswal JK, Patel PB, Wilson WR, Hicks KO, Bogle G. An agent-based model for drug-radiation interactions in the tumour microenvironment: hypoxia-activated prodrug SN30000 in multicellular tumour spheroids. PLoS Comput Biol. 2018;14(10):e1006469.

43. Jiang L, Shestov AA, Swain P, Yang C, Parker SJ, Wang QA, Terada LS, Adams ND, McCabe MT, Pietrak B, et al. Reductive carboxylation supports redox homeostasis during anchorage-independent growth. Nature. 2016; 532(7598):255-8.

\section{Publisher's Note}

Springer Nature remains neutral with regard to jurisdictional claims in published maps and institutional affiliations.

\section{Ready to submit your research? Choose BMC and benefit from:}

- fast, convenient online submission

- thorough peer review by experienced researchers in your field

- rapid publication on acceptance

- support for research data, including large and complex data types

- gold Open Access which fosters wider collaboration and increased citations

- maximum visibility for your research: over $100 \mathrm{M}$ website views per year

At $\mathrm{BMC}$, research is always in progress.

Learn more biomedcentral.com/submissions 